\title{
Polyunsaturated fatty acids and conjugated linoleic acid isomers in breast milk are associated with plasma non-esterified and erythrocyte membrane fatty acid composition in lactating women
}

\author{
Alexandre G. Torres*, Jacqueline G. Ney, Flávia Meneses and Nádia M. F. Trugo \\ Laboratório de Bioquímica Nutricional e de Alimentos, Instituto de Química, Universidade Federal do Rio de Janeiro, \\ Cidade Universitária, CT/ Bl. A, 21949-900, Rio de Janeiro, Brazil
}

(Received 17 June 2005 - Revised 21 September 2005 - Accepted 12 October 2005)

\begin{abstract}
Maternal adipose tissue is a major contributor to breast milk long-chain fatty acids, probably through the pool of plasma NEFA. The fatty acid composition of the erythrocyte membrane (EM) is a biochemical index of the intake of fatty acids not synthesized endogenously and of PUFA and long-chain PUFA fatty acid status. The present study investigated the associations between breast milk fatty acid composition and the composition of plasma NEFA and of EM fatty acids with special reference to PUFA, long-chain PUFA and conjugated linoleic acid (CLA). The detailed fatty acid composition of mature breast milk was also reported. Thirty-three healthy, lactating Brazilian women donated milk samples; of these, twenty-four also donated blood samples in an observational cross-sectional study. Breast milk fatty acid composition presented several associations with NEFA and EM composition, which explained most ( $\geq 50 \%)$ of the variability of selected milk PUFA, long-chain PUFA and CLA. Milk CLA was associated with fatty acids that are markers of dairy fat intake in the diet, NEFA and EM. In general, breast milk $n-3$ fatty acids and CLA, but not $n-6$ fatty acids, were associated with EM composition, whereas both the $n-6$ and $n-3$ fatty acids and CLA in milk were associated with NEFA composition, possibly owing to its role as a direct source of fatty acids for breast milk. These findings emphasize the contribution of the NEFA pool derived from the adipose tissue to the long-chain fatty acid composition of breast milk.
\end{abstract}

Fatty acid metabolism: Breast milk fatty acids: Non-esterified fatty acids: Erythrocyte fatty acids: Lactation

Maternal plasma lipids are the major direct source of the longchain $(>16 \mathrm{C}$ atoms) fatty acids present in human milk (Neville \& Picciano, 1997; Marangoni et al. 2002), because de novo synthesis in the mammary epithelial cells is almost exclusive for medium-chain fatty acids, and elongation and desaturation appear to be limited (Calabro et al. 1982; Neville \& Picciano, 1997). The maternal circulating fatty acids available to the mammary gland are those from VLDL triacylglycerols, which are synthesized in the liver; chylomicron triacylglycerols, from the maternal diet; and plasma NEFA, from maternal adipose tissue.

Long-chain fatty acids $(16: 0,18: 0,18: 1 n-9$ and $18: 2 n-6)$ from the maternal diet contribute directly, with approximately $30 \%$ of their contents in breast milk, as reported in studies using stable isotopes (Hachey et al. 1987; Demmelmair et al. 1998). Maternal adipose tissue probably contributes to the majority of the remaining $70 \%$ long-chain fatty acids present in milk (Koletzko \& Rodriguez-Palmero, 1999), since de novo synthesis of these fatty acids in the liver is limited (Hellerstein et al. 1991). Fat mobilization from adipose tissue may prevent acute variations in milk fatty acid composition, such as those that could be expected on a day-to-day or feed-to-feed basis.

Adipose tissue turnover is increased in lactating women owing to the unique hormonal milieu characteristic of human lactation
(Butte \& Hopkinson, 1998), which results in a higher plasma NEFA concentration in these women compared with non-lactating women (Butte et al. 1999; Torres et al. 2004). Moreover, lactation also appears to affect NEFA composition (Torres et al. 2004). The study of the possible associations between NEFA and milk fatty acids could help to elucidate the mechanisms and factors influencing long-chain fatty acid transfer to breast milk. These associations remain to be investigated.

The fatty acid composition of breast milk varies among different world regions, according to maternal dietary habits (Jensen, 1999). Erythrocyte membrane (EM) fatty acid composition is a biochemical index of intake of fatty acids not synthesized endogenously (Innis, 1992; Hunter, 1998; Torres et al. 2000), and of 18C PUFA and long-chain PUFA (LC-PUFA; $\geq 20$ C) status (Vlaardingerbroek \& Hornstra, 2004). Hence, the influence of habitual maternal fatty acid intake and status on breast milk composition may be investigated by determining the associations between the fatty acid composition of the EM and that of breast milk. The associations between milk fatty acid composition and EM fatty acid composition have not been fully explored.

The aim of the present study was to investigate the associations between human milk fatty acid composition, plasma NEFA composition and fatty acid composition of the EM, with special 
reference to associations involving $n-6$ and $n-3$ PUFA and LC-PUFA, and conjugated linoleic acid (CLA). Additionally, the detailed fatty acid composition of mature milk from lactating Brazilian women is also reported.

\section{Subjects and methods}

\section{Volunteers and data collection}

Adult nursing mothers attending a public day-care clinic in Rio de Janeiro with their babies were recruited for this cross-sectional study during their appointment with the paediatrician. Apparently healthy, well-nourished women ( $n$ 33) were enrolled in the study based on the following eligibility criteria:

1. Mother of a healthy, full-term, singleton infant, exclusively or predominantly breast-fed (breast milk plus a sparse use of water, water-based infusions, such as teas and herbs, or water-diluted fruit juices, without substituting for a breastfeed (World Health Organization, 1995))

2. Being 30-120 d postpartum at the time of milk collection.

3. A self-reported absence of chronic diseases or process of acute illness.

4. No intake of dietary supplements.

5. Age between 19 and 30 years.

6. Amenorrhoea.

The study protocol was approved by the Ethics Committee of the Municipal Health Secretary of Rio de Janeiro and was conducted in accordance with the Declaration of Helsinki. All participants signed an informed consent form prior to enrolment.

General data on maternal characteristics (socio-economic level and education, previous gestations, duration of gestation, use of supplements, days postpartum, age) were obtained through standardized questionnaires. Weight and height were measured on the day of the sample collection, and the BMI $\left(\mathrm{kg} / \mathrm{m}^{2}\right)$ was calculated.

Dietary intake was estimated through two $24 \mathrm{~h}$ recall questionnaires (24R) and one semi-quantitative food-frequency questionnaire (FFQ), which was adapted from Rocquelin et al. (1998), based on the habitual dietary intake by the urban population of Rio de Janeiro (Monteiro et al. 2000). The evaluation of the two $24 \mathrm{R}$ confirmed that all food sources of fat in the women's diet were included in the FFQ food list. To facilitate the maternal reporting of food portion sizes, a photographic index of foods was used. Daily nutrient intake was quantified by The Food Processor (ESHA Research, Salem, OR, USA) software, which utilizes food composition data from the US Department of Agriculture (United States Department of Agriculture - Agricultural Research Service, 2000), adapted for use of the most common fat sources in the Brazilian diet (NEPA/UNICAMP, 2004). To express the habitual average intake of fatty acids relative to energy intake, the $24 \mathrm{R}$ and the FFQ were used in combination, according to the following equation:

$$
\text { Nutrient intake }(\mathrm{en} \%)=[\mathrm{N}-\mathrm{FFQ} \times 37.6 \times \mathrm{F}-24 \mathrm{R} \times 100] /
$$$$
[\mathrm{F}-\mathrm{FFQ} \times \mathrm{E}-24 \mathrm{R}]
$$

where N-FFQ is the amount $(\mathrm{g})$ of the nutrient ingested as evaluated by the FFQ; F-24R is the amount $(\mathrm{g})$ of fat ingested as evaluated by the $24 \mathrm{R}$; F-FFQ is the amount $(\mathrm{g})$ of fat ingested as evaluated by the FFQ; E-24R is the total intake of energy $(\mathrm{kJ})$ as evaluated by the $24 \mathrm{R}$.

\section{Collection and storage of blood and breast milk samples}

Breast milk was collected once in the morning (08.00-10.00 hours) from all volunteers ( $n 33$ ), after fasting for approximately $11 \mathrm{~h}$. Milk was collected from the breast that was not suckled in the previous feeding, which occurred 90-180 min earlier (mean 135 (SD 38) min). Milk was completely expressed, using a manual syringestyle breast pump. Samples of the milk collected were stored in glass tubes at $-20^{\circ} \mathrm{C}$ until analysis.

Venous blood samples $(4 \mathrm{ml})$ were collected immediately before milk collection from twenty-four of the volunteers by venepuncture into tubes containing Na-EDTA as anticoagulant. Aliquots of whole blood were separated for immediate determination of haematocrit, by centrifugation in capillary tubes (Hemospin centrifuge; Incibrás, São Paulo, Brazil), and of haemoglobin concentration, by the cyanomethaemoglobin reaction (BioClin-Quibasa kit, São Paulo, Brazil). Plasma was separated by centrifugation and stored at $-20^{\circ} \mathrm{C}$ for later analysis of NEFA. The packed erythrocytes were washed three times with isotonic $\mathrm{NaCl}(0.9 \%, \mathrm{w} / \mathrm{v})$, after removal of the buffy coat. The washed erythrocytes were suspended in an equal volume of isotonic $\mathrm{NaCl}$ and stored at $-20^{\circ} \mathrm{C}$ with sodium dithionite at a final concentration of $1.0 \%(\mathrm{w} / \mathrm{v})$ in the erythrocyte suspension to avoid oxidation of unsaturated fatty acids (Broekhuyse, 1974).

\section{Analyses of milk, plasma and erythrocyte samples}

Milk fat contents were calculated from the milk fatty acid contents. The sum of all individual fatty acids, expressed as $\mathrm{mg} / \mathrm{dl}$ milk, identified in the gas-chromatographic analysis was multiplied by a correction factor of 1.05 (Jensen et al. 1997). Total milk protein was determined by the method of Lowry et al. (1951), as adapted by Trugo et al. (1988). The concentration of lactose in the milk samples was determined by the method of Perry \& Doan (1950).

For analysis of milk fatty acids, samples were defrosted in a water bath $\left(38^{\circ} \mathrm{C}\right)$ and homogenized by inversion and by agitation in an ultrasonic bath to disperse the coalesced fat. Total lipids were extracted from $1.0 \mathrm{ml}$ milk aliquots, in duplicate, using the method of Bligh \& Dyer (1959), essentially as described by Jensen et al. (1997). The chloroform extracts, containing 0.1\% (w/v) butyl-hydroxytoluene (Sigma Chemical Co., St Louis, MO, USA), were dried under $\mathrm{N}_{2}$, and the residue was suspended in $10.0 \mathrm{ml}$ chloroform-methanol $(10: 1, \mathrm{v} / \mathrm{v})$ and stored at $-20^{\circ} \mathrm{C}$ in glass vials with polytetrafluoroethylene-lined screw caps with an $\mathrm{N}_{2}$ atmosphere. Milk fatty acids were methylated by the use of the transesterification method described by Kramer et al. (1997).

Briefly, $5.0 \mathrm{ml}$ milk lipid extracts were transferred to glass tubes with polytetrafluoroethylene-lined screw caps and dried with an $\mathrm{N}_{2}$ stream. After the addition of internal standards (11:0 and 17:0; Sigma Chemical Co; $2.0 \mathrm{mg}$ of each $/ \mathrm{ml}$ hexane) and the solution of $\mathrm{NaOCH}_{3}$ in methanol at the appropriate concentration, samples were heated under $\mathrm{N}_{2}$ in a water bath $\left(50^{\circ} \mathrm{C}\right.$ for $10 \mathrm{~min}$ ) with agitation. After cooling, $\mathrm{HCl}$ in methanol $(10 \%, w / v)$ was added, and the tubes were closed under $\mathrm{N}_{2}$ and heated in a water bath $\left(80^{\circ} \mathrm{C}\right.$ for $10 \mathrm{~min}$, with agitation). The resulting fatty acid methyl esters (FAME) were extracted after adding hexane, vortex-mixing, adding aqueous $\mathrm{NaCl}(28.0 \%$, $\mathrm{w} / \mathrm{v})$, vortex-mixing and centrifugation $(500 \mathrm{~g}$ for $10 \mathrm{~min}$ at $26^{\circ} \mathrm{C}$ ). The superior hexane layer was evaporated, and the FAME were suspended with hexane $(70 \mu \mathrm{l} / \mathrm{g} \%$ fat in milk) and 
stored in appropriate vials until analysis. FAME were analysed by gas-chromatography as described by Torres et al. (2002b).

Erythrocyte suspensions $(250 \mu \mathrm{l})$ were transesterified with acetyl chloride (Merck, Darmstadt, Germany) as described by Lepage \& Roy (1986). Methylated samples were stored in hexane $(250 \mu \mathrm{l})$ with butyl-hydroxytoluene $(0 \cdot 05 \%$, w/v) under $\mathrm{N}_{2}$ at $-20^{\circ} \mathrm{C}$ for up to 1 week until analysis. Samples $(1.5 \mu \mathrm{l})$ were injected in the gas-chromatograph, operated as follows: $\mathrm{He}$ gas was used as a carrier $(70 \mathrm{kPa})$; the detector temperature was set at $270^{\circ} \mathrm{C}$; the injector temperature was $240^{\circ} \mathrm{C}$; the split ratio was $1: 15$; column temperature gradient was set at $200^{\circ} \mathrm{C}$ (held for $10 \mathrm{~min}$ ) $+1.5^{\circ} \mathrm{C} / \mathrm{min}$ to $210^{\circ} \mathrm{C}$ (held for $20 \mathrm{~min}$ ). NEFA were analysed by the method described in Ney et al. (2004), adapted from Polette et al. (1992) for splitless injections.

All samples (milk, plasma, erythrocytes) were analysed in a GC-14B gas-chromatograph (Shimadzu, Kyoto, Japan), using an Omegawax-320 column (Supelco Co., Bellefonte, PA, USA). All the materials used for sample storage and analysis were thoroughly rinsed with alcoholic $\mathrm{KOH}(2.5 \%$, w/v) and soaked in $\mathrm{H}_{2} \mathrm{NO}_{3}(13 \%$, w/v) for at least $2 \mathrm{~h}$. All organic solvents used were of chromatographic grade (Tedia, São Paulo, Brazil) and were periodically tested for the presence of peroxides (Merkoquant test stripes; Merck). Samples were analysed as duplicates, and inter- and intra-assay coefficients of variation for the gaschromatographic analyses have previously been reported (Torres et al. 2002b, Ney et al. 2004).

\section{Identification and quantification of fatty acids}

Gas-chromatographic peaks of FAME were identified by comparing the retention time data of certified standards with the sample retention data, expressed as relative retention times (Torres et al. $2002 b$ ). The FAME standard mixtures used were 37 FAME Mix and Menhaden oil FAME Mix (refs $47885-\mathrm{U}$ and 47116 , respectively; Supelco Co.). The standards for the conjugated octadecadienoic acids $18: 2-9 c, 11 \mathrm{t}, 18: 2-10 t, 12 c, 18: 2-9 t, 11 t, 18: 2-$ $10 t, 12 t, 18: 2-10 c, 12 c$ were a generous gift from Dr Robert Adlof (Agricultural Research Service, Food Quality \& Safety Research Unit, US Department of Agriculture, Peoria, IL, USA).

Peaks eluting at the retention times of the CLA standards were confirmed to be octadecadienoic acids by GC-MS, as described in Torres et al. (2002b). The GC column used for the analyses did not separate CLA isomers with double bonds in different positions. Therefore, two of the identified CLA peaks were designated $18: 2-c, c$ and $18: 2-t, t$, since each peak could represent a mixture of isomers. The data on the $18: 2-9 c, 11 t$ (rumenic acid) and $18: 2-10 t, 12 c$ isomers are presented with the positions of the double bonds indicated, because these are probably the major CLA present at the cis,trans and trans, cis chromatographic peaks according to published data on the CLA content of dairy fat (Lin et al. 1995) and breast milk (Park et al. 1999). The mathematical method described by Torres et al. $(2002 a)$ was used to confirm the identities of fatty acids reported and to identify FAME peaks not present in the standard mixtures.

In all the milk samples, three isomers of octadecaenoic acid were present $-18: 1 n-9,18: 1 n-7$ and $18: 1 n-5$ - but the resolution of these three peaks was dependent on the area of the 18: $1 n-9$ peak. The areas of these peaks were summed, and the results were expressed as ' $18: 1$ '. Peak areas were used for calculating the concentration of fatty acids. After correcting the peak areas with Ackman and Sipos theoretical correction factors, as described by Wolff et al. (1995), the weight percentages of fatty acids ( $\mathrm{g} / 100 \mathrm{~g}$ total fatty acids) were calculated for all the samples. For the milk samples, the concentrations of fatty acids, expressed as $\mathrm{mg} / \mathrm{dl}$, were also calculated using peak areas of the internal standards 11:0 (for FAME peaks eluting before 12:0) and 17:0 (for all other FAME peaks). Some fatty acids were not identified in all samples and were considered as missing values for statistical analysis.

\section{Statistical analysis}

Descriptive analysis was used to calculate means, geometric means, standard deviations, and standardized coefficients of kurtosis and skewness. Variables with standardized skewness coefficients higher than $+2 \cdot 0$ were transformed $(\mathrm{x}=\ln \mathrm{x})$ before statistical analysis, and the geometric mean is presented in Tables as appropriate. All variables had kurtosis coefficients of between $-2 \cdot 0$ and $+2 \cdot 0$, and no variable had a skewness coefficient of less than $-2 \cdot 0$.

Pearson correlation analysis was used to investigate associations between milk fatty acid composition and habitual maternal diet, NEFA composition, and EM fatty acid composition. Stepwise multiple regression analysis was performed between selected breast milk PUFA, LC-PUFA and milk CLA, and independent variables from NEFA and EM fatty acid composition. Fatty acids were included as independent variables based on biological relevance and/or on the results of the Pearson correlation analysis. The final models were further evaluated using their respective normal probability plots. Multifactor ANOVA with Tukey's post hoc test was used to investigate the influence of factors, categorized as ' $<$ median' and ' $\geq$ median' (age, parity, BMI, lactational period) on continuous variables (PUFA, LC-PUFA and CLA contents of breast milk). Two-sided $P$ values of $<0.05$ were considered to be statistically significant, and when $0.05 \leq P<0 \cdot 10$, results were considered as tendencies for significance. All statistical analyses were performed on Statgraphics v. 7 (Statistical Graphics Corporation, Manugistics, Inc., Cambridge, MA, USA).

\section{Results}

Table 1 presents the general characteristics of the volunteers, including the intake of energy and lipid-related nutrients. The average BMI lay within the range of BMI for eutrophic populations (World Health Organization, 1995). The average energy intake of the volunteers is compatible with an under-reporting of food intake (energy intake/estimated basal energy expenditure $<1.3$; Macdiarmid \& Blundell, 1998). Total lipid intake contributed approximately $29 \%$ of the total energy intake of the volunteers. PUFA contributed approximately $20 \%$ of total lipid intake, and $n-6$ fatty acids were the main $(>80 \%)$ PUFA in the diet.

Dairy fat, which is also a rich source of CLA, contributed $57 \%$ and $34 \%$ of the intake of saturated fatty acids and MUFA, respectively. Vegetable oils, mainly soyabean oil, were the main sources of $n-6(61 \%)$ and $n-3$ PUFA (52\%). Fish and fish oils, of which the intake was low, contributed only $4 \%$ of the intake of $n$-3 PUFA.

The mean contents of total fat, lactose and protein in the breast milk of the volunteers were, respectively: 29.6 (SD 3.0), 75.5 (SD 2.8), $15 \cdot 3$ (SD 0.7) g/l. 
Table 1. General characteristics and dietary intake of energy and lipidrelated nutrients of the lactating women $(n 33)$

\begin{tabular}{lcc}
\hline & Mean & SEM \\
\hline Characteristic & & \\
Age (years) & $26 \cdot 0$ & $1 \cdot 1$ \\
BMI (kg/m ${ }^{2}$ ) & $24 \cdot 1$ & 0.6 \\
Lactation period (d) & $58 \cdot 2$ & $5 \cdot 2$ \\
Parity & 1.4 & $0 \cdot 1$ \\
Haematocrit (\%) & 38.5 & 0.8 \\
Haemoglobin (g/dl) & $12 \cdot 1$ & 0.3 \\
Dietary intake & & \\
Energy (kJ) & 6905 & 395 \\
Total fat (en \%) & 28.5 & 1.4 \\
Saturated (en \%) & 11.3 & 0.8 \\
Monounsaturated (en \%) & 9.7 & 0.5 \\
Polyunsaturated (en \%) & 5.7 & 0.4 \\
P:S & 0.55 & 0.04 \\
$n-3$ (en \%) & 0.72 & 0.05 \\
$n-6$ (en \%) & 4.82 & 0.36 \\
$n-6 / n-3$ & 6.8 & 0.3 \\
\hline
\end{tabular}

en $\%$, nutrient intake relative to energy intake (\%); P:S, polyunsaturated to saturated fat ratio.

Table 2 presents the fatty acid percentage composition $(\mathrm{g} / 100 \mathrm{~g}$ total fatty acids) of the breast milk samples. Oleic acid $(18: 1 n-9)$ was the main octadecaenoic acid in the samples, contributing 87.8 (SD 2.6) $\%$ to the total 18:1 value. Four CLA isomers were identified in the samples. According to the multifactorial ANOVA analyses, age, parity, BMI and lactational period did not affect the weight percentage composition of breast milk PUFA, LC-PUFA or CLA.

The concentrations of milk medium-chain fatty acids were negatively correlated with the habitual intake of saturated $(r-0.55, P=0.002)$, monounsaturated $(r-0.54, P=0.003)$ and polyunsaturated $(r-0.41, P=0.031)$ lipids, and with the intake of the essential fatty acids linoleic $(18: 2 n-6 ; r-0.39$, $P=0.040)$ and $\alpha$-linolenic $(18: 3 n-3 ; r-0.48, P=0.011)$. These results are consistent with the known inhibitory effect of lipid intake on the de novo synthesis of medium-chain fatty acids by the lactating mammary epithelium (Neville \& Picciano, 1997). The dietary intake of CLA was not evaluated, but the $18: 2-9 c, 11 t, \quad 18: 2-c, c$ and $18: 2-t, t$ contents of the milk samples correlated $(P<0.05)$ with the intakes of fatty acids 15:0 $(r$ 0.50, 0.48 and 0.60, respectively) and 17:0 $(r$ 0.61, 0.44 and 0.45 , respectively), which could be explained by their common food source being mainly dairy fat (Kramer et al. 1997; United States Department of Agriculture - Agricultural Research Service, 2000). A correlation between the content in milk of a particular fatty acid and its respective dietary intake level was found only for 15:0 ( $r$ 0.38, $P=0.047)$ and $18: 1(r 0.56, P=0.002)$, but tendencies were found for linoleic $(r 0.35, P=0.070)$ and $\alpha$-linolenic $(r$ 0.36, $P=0.057)$ acids.

The data for the EM and plasma NEFA composition of the lactating women ( $n$ 24) are presented in Table 3. The conjugated linoleic acid 18:2-9c,11t (rumenic acid) was identified in both EM and NEFA.

Pearson correlation analysis was used to investigate the associations between breast milk fatty acid composition, expressed as $\mathrm{g} / 100 \mathrm{~g}$ total fatty acids and as $\mathrm{mg} / \mathrm{dl}$ milk, and the fatty acid composition of the EM and of plasma NEFA. A greater number of significant correlations were found for milk fatty acids expressed as $\mathrm{g} / 100 \mathrm{~g}$ than for fatty acids as $\mathrm{mg} / \mathrm{dl}$. Therefore, only the results concerning the contents of milk fatty acids expressed as $\mathrm{g} / 100 \mathrm{~g}$, with an emphasis on PUFA, LC-PUFA and CLA, are presented in Tables 4 and 5.

Table 2. Fatty acid contents ( $\mathrm{g} / 100 \mathrm{~g}$ total fatty acids) in milk from Brazilian lactating women ( $n$ 33)

\begin{tabular}{|c|c|c|c|c|c|c|c|c|}
\hline \multicolumn{3}{|l|}{ Saturated* } & $i 16: 0$ & 0.076 & 0.035 & \multicolumn{3}{|c|}{ Conjugated linoleic acid } \\
\hline $8: 0$ & 0.24 & 0.066 & $i 17: 0$ & 0.14 & 0.062 & $18: 2-10 t, 12 c$ & $0.017(0.015)$ & 0.009 \\
\hline $9: 0$ & 0.01 & 0.00 & $a 17: 0$ & $0 \cdot 19$ & 0.070 & $18: 2-c, c$ & 0.017 & 0.007 \\
\hline $10: 0$ & $1 \cdot 76$ & 0.51 & $i 18: 0$ & $0.041(0.036)$ & 0.022 & $18: 2-t, t$ & 0.072 & 0.018 \\
\hline $14: 0$ & $6.79(6.34)$ & $2 \cdot 62$ & $a 20: 0$ & $0.083(0.073)$ & 0.043 & $18: 3 n-6$ & $0 \cdot 17$ & 0.052 \\
\hline $15: 0$ & 0.32 & $0 \cdot 11$ & \multicolumn{3}{|c|}{ Monounsaturated } & $20: 2 n-6$ & 0.35 & 0.069 \\
\hline $16: 0$ & $19 \cdot 7$ & $1 \cdot 7$ & $10: 1 n-7$ & 0.015 & 0.006 & $20: 3 n-6$ & $0.43(0.42)$ & $0 \cdot 11$ \\
\hline $18: 0$ & $6 \cdot 28$ & 1.07 & $12: 1 n-7$ & $0.016(0.014)$ & 0.012 & $20: 4 n-6$ & $0.47(0.46)$ & $0 \cdot 13$ \\
\hline $19: 0$ & 0.026 & 0.011 & $14: 1 n-7$ & $0.024(0.023)$ & 0.007 & $20: 5 n-6$ & $0.015(0.013)$ & 0.010 \\
\hline $20: 0$ & 0.17 & 0.027 & $14: 1 n-5$ & $0.21(0.20)$ & 0.078 & $22: 2 n-6$ & $0.054(0.051)$ & 0.019 \\
\hline \multicolumn{3}{|c|}{ Branched-chain $†$} & $18: 1 \ddagger$ & $32 \cdot 4$ & $4 \cdot 25$ & $18: 4 n-3$ & 0.032 & 0.014 \\
\hline$i 12: 0$ & $0.020(0.018)$ & 0.010 & $19: 1 n-9$ & 0.057 & 0.021 & $20: 3 n-3$ & 0.045 & 0.013 \\
\hline a13:0 & $0.018(0.016)$ & 0.008 & $20: 1 n-9$ & 0.35 & 0.091 & $20: 4 n-3$ & $0.090(0.086)$ & 0.031 \\
\hline a14:0 & $0.038(0.032)$ & 0.023 & $20: 1 n-7$ & 0.046 & 0.011 & $20: 5 n-3$ & $0.071(0.062)$ & 0.048 \\
\hline$i 15: 0$ & 0.095 & 0.049 & $20: 1 n-5$ & 0.028 & 0.015 & $22: 5 n-3$ & $0.16(0.14)$ & 0.074 \\
\hline \multirow[t]{2}{*}{$a 15: 0$} & $0.12(0.099)$ & 0.067 & $22: 1 n-9$ & $0.065(0.063)$ & 0.017 & $22: 6 n-3$ & $0.22(0.20)$ & 0.097 \\
\hline & & & $24: 1 n-9$ & $0.033(0.017)$ & 0.071 & & & \\
\hline
\end{tabular}

* Straight-chain saturated fatty acids.

† Branched-chain saturated fatty acids.

\# Includes the $18: 1 n-9,18: 1 n-7$ and $18: 1 n-5$ isomers.

Values in parentheses are geometric means of variables with non-normal distributions. 
Table 3. Fatty acid contents ( $\mathrm{g} / 100 \mathrm{~g}$ total fatty acids) of erythrocyte membrane (EM) and plasma NEFA in lactating Brazilian women ( $n$ 24)

\begin{tabular}{|c|c|c|c|c|c|c|c|c|c|}
\hline \multirow[b]{2}{*}{ Fatty acid } & \multicolumn{2}{|l|}{ EM } & \multicolumn{2}{|c|}{ NEFA } & \multirow[b]{2}{*}{ Fatty acid } & \multicolumn{2}{|l|}{ EM } & \multicolumn{2}{|c|}{ NEFA } \\
\hline & Mean & SD & Mean & SD & & Mean & SD & Mean & SD \\
\hline Saturated & & & & & Conjugated linole & eic acid & & & \\
\hline $14: 0$ & - & - & $1.31(1.30)$ & 0.21 & $18: 2-9 c, 11 t$ & $0.17(0.13)$ & 0.16 & 0.61 & 0.10 \\
\hline $15: 0$ & - & - & 0.44 & 0.09 & Polyunsaturated & & & & \\
\hline $16: 0$ & $24 \cdot 9$ & 2.49 & $34 \cdot 1$ & $2 \cdot 22$ & $18: 2 n-6$ & $9 \cdot 65$ & 1.32 & $17 \cdot 8$ & 1.92 \\
\hline $17: 0$ & $0.69(0.61)$ & 0.41 & - & - & $18: 3 n-6$ & $0.14(0.13)$ & 0.05 & $0.24(0.22)$ & 0.12 \\
\hline $18: 0$ & $18 \cdot 2$ & 1.88 & $13 \cdot 1$ & 1.64 & $20: 2 n-6$ & $0.39(0.35)$ & 0.21 & $0.28(0.27)$ & 0.11 \\
\hline $20: 0$ & 0.43 & 0.07 & - & - & $20: 3 n-6$ & $1.36(1.30)$ & 0.42 & $0.58(0.55)$ & 0.22 \\
\hline $22: 0$ & $2 \cdot 06$ & 0.30 & - & - & $20: 4 n-6$ & 11.52 & 1.79 & 2.35 & 0.57 \\
\hline $24: 0$ & $5 \cdot 29$ & 1.01 & - & - & $22: 4 n-6$ & $2 \cdot 60$ & 0.51 & - & - \\
\hline Monounsaturated & & & & & $22: 5 n-6$ & $0.62(0.58)$ & 0.25 & - & - \\
\hline $16: 1 n-7$ & $0.65(0.61)$ & 0.25 & $2.95(2.87)$ & 0.76 & $18: 3 n-3$ & $0.10(0.09)$ & 0.02 & 0.63 & 0.09 \\
\hline $18: 1 n-9$ & 11.0 & 1.43 & $21 \cdot 3(21 \cdot 0)$ & 3.54 & $18: 4 n-3$ & 0.19 & 0.13 & - & - \\
\hline $18: 1 n-7$ & $1.74(1.71)$ & 0.35 & 2.64 & 0.37 & $20: 5 n-3$ & $0.33(0.30)$ & 0.18 & 0.42 & 0.14 \\
\hline $20: 1 n-9$ & $0.19(0.18)$ & 0.09 & 0.40 & 0.13 & $22: 5 n-3$ & 1.42 & 0.37 & - & - \\
\hline $22: 1 n-9$ & trace & - & 1.39 & 0.37 & $22: 6 n-3$ & $3 \cdot 73$ & 0.46 & - & - \\
\hline $24: 1 n-9$ & $2 \cdot 65$ & 0.91 & 0.45 & 0.11 & & & & & \\
\hline
\end{tabular}

Values in parentheses are geometric means of variables with non-normal distributions.

Breast milk fatty acid composition presented several correlations with EM fatty acids (Table 4), especially with polyunsaturated ones. Milk CLA were positively correlated with EM rumenic acid. Direct correlations between the content of fatty acids in breast milk and the respective content in EM occurred for two fatty acids, $18: 3 n-3$ and $20: 5 n-3$ (EPA). Two correlations between a metabolic product in milk $(22: 6 n-3)$ and precursors in the EM $(18: 3 n-3$ and $20: 5 n-3)$ were found.

Several significant correlations were found between breast milk fatty acids and NEFA composition (Table 5). As with the results of the correlation analyses between milk and erythrocytes, milk PUFA were the fatty acids that provided the majority of the significant correlations with NEFA composition. Plasma $18: 2 n-6$ correlated negatively with milk $22: 4 n-6$ and $22: 5 n-6$, and tended to correlate with 20:4n-6 (arachidonic acid; $r-0 \cdot 40, P=0 \cdot 065$ )

In contrast to the results for the correlation analyses between milk and EM, several milk fatty acids correlated positively with their respective contents in plasma NEFA, as was the case for $20: 3 n-6,20: 4 n-6,18: 3 n-3$ and $20: 5 n-3$ (Table 5). Other milk fatty acids, $15: 0(r 0 \cdot 38, P=0 \cdot 080), 18: 2 n-6(r 0 \cdot 39, P=0 \cdot 075)$ and 18:2-9c,11t $(r \quad 0 \cdot 37, P=0.090)$ tended to correlate with their respective plasma contents. In further contrast with the results for the erythrocyte correlation analyses, several positive correlations between some LC-PUFA in milk and their respective metabolic precursors in NEFA were found. Additionally, milk $22: 6 n-3$ (DHA) tended to correlate $(r 0.42, P=0.075)$ with plasma $20: 5 n-3$

In order to further investigate and characterize the association of NEFA and EM fatty acids with breast milk PUFA and CLA composition, a series of multiple regression analyses were performed. The results for the models of biologically relevant PUFA and CLA are presented in Table 6. All the significant regression models resulted in adjusted $R^{2}>0.60$ and $P<0.005$ (ANOVA), with the exception of the model for 18:2-c,c. Independent variables (NEFA or EM fatty acids) that presented $P>0.05$ for their respective coefficients were maintained in the models when their inclusion resulted in the best models, according to the adjusted $R^{2}$ and the mean absolute error of estimated value. For most of the resulting models, the coefficients for the fatty acids selected as independent variables were consistent with the results of Pearson correlation analysis, with the exception of the model for milk arachidonic acid. In most models for milk PUFA or LC-PUFA, EM linoleic acid showed negative coefficients. No significant multiple regression model could explain the variation in linoleic acid and $18: 2-10 t, 12 c$ content in breast milk.

Table 4. Pearson correlations between breast milk fatty acids and erythrocyte membrane (EM) fatty acids

\begin{tabular}{|c|c|c|c|c|c|c|c|c|c|}
\hline Milk & EM & $r$ & $P$ & $n$ & Milk & EM & $r$ & $P$ & $n$ \\
\hline \multicolumn{5}{|c|}{ Conjugated linoleic acid } & \multicolumn{5}{|l|}{$n-3$ (cont.) } \\
\hline $18: 2-t, t$ & $18: 2-9 c, 11 t$ & 0.64 & 0.014 & 14 & $18: 3 n-3$ & $18: 3 n-3$ & 0.52 & 0.034 & 17 \\
\hline $18: 2-c, c$ & $18: 2-9 c, 11 t$ & 0.70 & 0.004 & 15 & $20: 5 n-3$ & $18: 2 n-6$ & -0.84 & 0.000 & 24 \\
\hline$n-6$ & & & & & $20: 5 n-3$ & $20: 5 n-3$ & 0.61 & 0.002 & 23 \\
\hline $20: 3 n-6$ & $18: 2 n-6$ & -0.68 & 0.000 & 24 & $20: 5 n-3$ & $n-6$ & -0.66 & 0.000 & 24 \\
\hline $20: 4 n-6$ & $18: 2 n-6$ & -0.62 & 0.001 & 24 & $20: 5 n-3$ & $n-3$ & 0.57 & 0.004 & 24 \\
\hline $22: 4 n-6$ & $18: 2-9 c, 11 t$ & 0.52 & 0.033 & 17 & $22: 5 n-3$ & $18: 2 n-6$ & -0.58 & 0.003 & 24 \\
\hline $22: 4 n-6$ & $18: 2 n-6$ & -0.74 & 0.000 & 24 & $22: 6 n-3$ & $18: 2 n-6$ & -0.56 & 0.005 & 24 \\
\hline $22: 5 n-6$ & $18: 2 n-6$ & -0.71 & 0.000 & 24 & $22: 6 n-3$ & $18: 3 n-3$ & 0.53 & 0.030 & 17 \\
\hline$n-3$ & & & & & $22: 6 n-3$ & $20: 5 n-3$ & 0.69 & 0.000 & 23 \\
\hline $18: 3 n-3$ & $18: 1 n-9$ & -0.49 & 0.015 & 24 & $22: 6 n-3$ & $n-3$ & 0.49 & 0.015 & 24 \\
\hline
\end{tabular}

$n$, number of samples with pairwise data for the corresponding variables. 
Table 5. Pearson correlations between breast milk fatty acids and plasma NEFA

\begin{tabular}{lcrcr}
\hline Milk & NEFA & $r$ & $P$ & $n$ \\
\hline Saturated & & & & \\
MCFA & $18: 1 n-9$ & -0.47 & 0.028 & 24 \\
MCFA & $18: 2-9 c, 11 t$ & -0.44 & 0.038 & 24 \\
Conjugated linoleic acid & & & \\
$18: 2-t, t$ & $15: 0$ & 0.46 & 0.048 & 21 \\
$18: 2-t, t$ & $18: 2-9 c, 11 t$ & 0.52 & 0.022 & 21 \\
$n-6$ & & & & \\
$20: 3 n-6$ & $18: 1 n-9$ & -0.43 & 0.044 & 24 \\
$20: 3 n-6$ & $20: 3 n-6$ & 0.66 & 0.002 & 22 \\
$20: 4 n-6$ & $20: 3 n-6$ & 0.45 & 0.048 & 22 \\
$20: 4 n-6$ & $20: 4 n-6$ & 0.53 & 0.010 & 24 \\
$22: 4 n-6$ & $18: 2 n-6$ & -0.46 & 0.032 & 24 \\
$22: 4 n-6$ & $20: 3 n-6$ & 0.44 & 0.049 & 22 \\
$22: 4 n-6$ & $20: 4 n-6$ & 0.52 & 0.014 & 24 \\
$22: 5 n-6$ & $18: 2 n-6$ & -0.43 & 0.048 & 24 \\
$22: 5 n-6$ & $20: 4 n-6$ & 0.59 & 0.004 & 24 \\
$n-3$ & $18: 1 n-9$ & & & \\
$18: 3 n-3$ & $18: 3 n-3$ & -0.59 & 0.004 & 24 \\
$18: 3 n-3$ & $20: 5 n-3$ & 0.54 & 0.010 & 24 \\
$20: 5 n-3$ & $20: 5 n-3$ & 0.51 & 0.025 & 21 \\
$22: 5 n-3$ & 0.54 & 0.017 & 21 \\
\hline
\end{tabular}

MCFA, sum of medium-chain fatty acids $10: 0,12: 0$ and 14:0 contents; $n$, number of samples with pairwise data for the corresponding variables.

\section{Discussion}

The general pattern of the fatty acid composition (contents of short-, medium-, and odd-chain saturated, as well as of MUFA and PUFA) of breast milk from lactating women in the present study was similar to that reported for the milk of lactating women from Western developed countries (Jensen et al. 1995; Jensen, 1999), as well as from different Brazilian regions (Cunha et al. 2005; Silva et al. 2005). These similarities might result from the transition in nutrition that is occurring in Brazil (Monteiro et al. 1995). The detailed fatty acid composition of milk, with the identification of sixty-seven fatty acids, including the contents of branched-chain and conjugated octadecadienoic acids, has not been reported in other studies of Brazilian women (Cunha et al. 2005; Silva et al. 2005), except in preliminary studies carried out by our own research group (Torres et al. $2002 a, b)$. Moreover, some fatty acids reported here and in our previous studies (Torres et al. 2002b) have, to our knowledge, not yet been reported for other populations.

The milk of Brazilian women presented a different distribution pattern of CLA isomers and higher amounts of rumenic acid than milk from German and North-American mothers (Jensen et al. 1995; Jensen, 1999; Park et al. 1999). These differences may be attributed to the CLA content of Brazilian beef and dairy products. Cattle fed on pasture, which is the case for Brazilian cattle throughout the year, tend to have a higher content of CLA in their milk and meat (Precht \& Molkentin, 1997). As the biological effects of CLA in vivo are potent and are not shared by all isomers (Pariza et al. 2000), an evaluation of the isomeric distribution and total CLA content of breast milk is important in order to evaluate the exposure of breast-fed infants to these effects. The CLA content of breast milk may be used as a marker of dairy fat intake as it was associated in the present study not only with EM and NEFA CLA, but also with other fatty acids from dairy products in the diet, the EM and NEFA.

Table 6. Multiple regression analysis for modelling of breast milk PUFA and conjugated linoleic acids contents

\begin{tabular}{|c|c|c|c|c|c|c|c|}
\hline $\begin{array}{l}\text { Breast milk fatty acid } \\
\text { (dependent variable) }\end{array}$ & $\begin{array}{l}\text { Blood fatty acids } \\
\text { (independent variables) }\end{array}$ & Coefficient & $P$ & MAE & MRE (\%) & Adjusted $R^{2}$ & ANOVA for the model $(P)$ \\
\hline \multirow[t]{4}{*}{$22: 6 n-3$} & Constant & 0.439 & 0.029 & & & & \\
\hline & EM $18: 2 n-6$ & -0.042 & 0.024 & 0.042 & 19 & 0.63 & 0.0011 \\
\hline & $18: 3 n-3$ & 1.296 & 0.060 & & & & \\
\hline & $20: 5 n-3$ & 0.288 & 0.026 & & & & \\
\hline \multirow[t]{4}{*}{$20: 5 n-3$} & Constant & 0.276 & 0.097 & & & & \\
\hline & EM $18: 2 n-6$ & -0.029 & 0.008 & 0.023 & 32 & 0.76 & 0.0000 \\
\hline & $20: 5 n-3$ & 0.132 & 0.045 & & & & \\
\hline & NEFA $20: 5 n-3$ & 0.062 & 0.066 & & & & \\
\hline \multirow[t]{4}{*}{$18: 3 n-3$} & Constant & 0.929 & 0.056 & & & & \\
\hline & EM $18: 3 n-3$ & 0.846 & 0.728 & 0.111 & 10 & 0.62 & 0.0019 \\
\hline & NEFA $18: 1 n-9$ & -0.038 & 0.007 & & & & \\
\hline & $18: 3 n-3$ & 1.436 & 0.025 & & & & \\
\hline \multirow[t]{6}{*}{$20: 4 n-6$} & Constant & 1.675 & 0.000 & & & & \\
\hline & EM 18:2n-6 & -0.105 & 0.000 & 0.045 & 10 & 0.77 & 0.0002 \\
\hline & $20: 3 n-6$ & 0.137 & 0.038 & & & & \\
\hline & $20: 4 n-6$ & -0.045 & 0.007 & & & & \\
\hline & NEFA $20: 3 n-6$ & -0.086 & 0.428 & & & & \\
\hline & $20: 4 n-6$ & 0.092 & 0.054 & & & & \\
\hline \multirow[t]{4}{*}{$18: 2-9 c, 11 t$} & Constant & -0.347 & 0.032 & & & & \\
\hline & EM 17:0 & 0.586 & 0.007 & 0.056 & 13 & 0.75 & 0.0013 \\
\hline & $18: 2-9 c, 11 t$ & $2 \cdot 078$ & 0.000 & & & & \\
\hline & NEFA $15: 0$ & 0.360 & 0.099 & & & & \\
\hline \multirow[t]{3}{*}{$18: 2-c, c$} & Constant & -0.004 & 0.511 & & & & \\
\hline & EM 17:0 & 0.062 & 0.006 & 0.002 & 11 & 0.50 & 0.0182 \\
\hline & $18: 2-9 c, 11 t$ & 0.018 & 0.045 & & & & \\
\hline \multirow[t]{3}{*}{$18: 2-t, t$} & Constant & -0.006 & 0.740 & & & & \\
\hline & EM $18: 2-9 c, 11 t$ & 0.077 & 0.014 & 0.009 & 12 & 0.61 & 0.0038 \\
\hline & NEFA $18: 2-9 c, 11 t$ & 0.106 & 0.006 & & & & \\
\hline
\end{tabular}

MAE, mean absolute error of value estimated using the model; MRE, mean relative error of estimated value; EM, erythrocyte membrane. 
Human adipose tissue probably has a definite intermediary role in the transfer of long-chain fatty acids from the maternal diet to milk (Martin et al. 1993; Demmelmair et al. 1998; Koletzko \& Rodriguez-Palmero, 1999). Therefore, fatty acids mobilized from adipose tissue that circulate in blood as NEFA are possibly important direct sources of long-chain fatty acids for the mammary gland. This is the first study to demonstrate the association between breast milk fatty acid composition and NEFA composition.

There is certainly a time interval between the appearance of a particular fatty acid in the plasma as NEFA and its secretion into the milk. Even though blood and milk samples were collected at the same time, after an overnight fast, it is expected that the NEFA composition reflects the fatty acids habitually available by the lipolysis of adipose tissue when a healthy individual is kept on a relatively constant diet. As the kinetics of fatty acid turnover in adipose tissue are relatively slow (Katan et al. 1997), and its mass is large, it is unlikely that the pattern of NEFA composition during short-term fasting varies within a period of a few weeks.

Some breast milk PUFA and LC-PUFA were negatively associated with the contents of linoleic and oleic acids in the EM or NEFA, which may reflect the competition between these fatty acids for transfer into milk. Fatty acid metabolism is extremely competitive in nature, and chain length, and the number and position of the double bonds, are the main molecular characteristics determining the specificity of enzymes and binding proteins for fatty acids (Jones \& Kubow, 1999). Linoleic and oleic acids are the most abundant unsaturated fatty acids in the plasma, and their elevated levels may be unfavourable for PUFA and LCPUFA transfer into breast milk. This might be of special concern when the maternal intake of linoleic acid is relatively high compared with the LC-PUFA intake, as in the present study.

On the other hand, several milk PUFA and LC-PUFA were positively associated with their respective contents and/or the contents of their metabolic precursors in NEFA and in the EM. Although the positive associations found in the present study between LC-PUFA in milk and their metabolic precursors in NEFA could be indirect and derived from other metabolic processes, they suggest that chain elongation and/or desaturation might occur in the mammary epithelium. In the case of the EM, positive associations were found only for $n-3$ fatty acids. It is possible that a metabolic pool rich in $n-3$ fatty acids, such as plasma lysophospholipids, which are a source of DHA for the EM (Brossard et al. 1997), might also be a source of $n$-3 PUFA and LC-PUFA for breast milk.

In the multiple regression models, most of the variation $\left(R^{2}>0.60\right)$ of the main PUFA and LC-PUFA in breast milk, with the exception of linoleic acid, could be explained by the variation in NEFA and EM fatty acids. The lack of a significant model for breast milk linoleic acid is consistent with the lack of significant Pearson correlations of this variable with NEFA and EM fatty acids. Marangoni et al. (2002) found a significant correlation between linoleic acid in mature milk and its content in total plasma lipids during fasting. It is possible that the contribution of linoleic acid from plasma lipoproteins, owing to its abundance, to the milk content may prevail over the contribution that could be derived from plasma NEFA. It was not possible to model individual breast milk fatty acids contents with variables derived from just one of the metabolic pools studied (NEFA or EM), with the exception of DHA and 18:2-c,c, for which most of the variability could be explained solely by EM-derived variables.
In conclusion, both NEFA and EM fatty acids explained most of the variability in the selected milk PUFA, LC-PUFA and CLA. In general, breast milk $n-3$ and CLA but not $n-6$ fatty acids were associated with EM composition, whereas both the $n-6$ and $n-3$ series and CLA in human milk were associated with NEFA composition. There was a greater number of direct correlations between a fatty acid in milk and its content in NEFA than between milk and the EM. The contrasts between EM and NEFA are possibly due to the role of NEFA as a direct source of fatty acids for breast milk. These findings emphasize the contribution of the NEFA pool derived from adipose tissue to the long-chain fatty acid composition of breast milk.

\section{Acknowledgements}

The authors thank the women who volunteered to participate in this study. A. G. T. thanks Tatiana El-Bacha for critically reading the manuscript. This study was supported by Coordenação de Aperfeiçoamento de Pessoal de Ensino Superior (CAPES), Conselho Nacional de Desenvolvimento Científico e Tecnológico (CNPq) and Fundação Carlos Chagas Filho de Amparo à Pesquisa do Estado do Rio de Janeiro (FAPERJ), Brazil. A. G. T and F. M. were recipients of $\mathrm{PhD}$ fellowships $(\mathrm{CNPq})$, J. G. N. was in receipt of a research assistant fellowship $(\mathrm{CNPq})$, and N. M. F. T. is a Research Fellow of CNPq.

\section{References}

Bligh EG \& Dyer WJA (1959) A rapid method of total lipid extraction and purification. Can J Biochem Physiol 37, 911-917.

Broekhuyse RM (1974) Long-term storage of erythrocytes for quantitative analyses of lipids. Clin Chim Acta 52, 53-58.

Brossard N, Croset M, Normand S, Pousin J, Lecerf J, Laville M, Tayot JL \& Lagarde M (1997) Human plasma albumin transports [13C]docosahexaenoic acid in two lipid forms to blood cells. J Lipid Res 38, $1571-1582$

Butte NF \& Hopkinson JM (1998) Body composition changes during lactation are highly variable among women. $J$ Nutr 128, 381S-385S.

Butte NF, Hopkinson JM, Mehta N, Moon JK \& Smith EO'B (1999) Adjustments in energy expenditure and substrate utilization during late pregnancy and lactation. Am J Clin Nutr 69, 299-307.

Calabro MA, Prasad MR, Wakil SJ \& Joshi VC (1982) Stearoyl-coenzyme A desaturase activity in the mammary gland and liver of lactating rats. Lipids 17, 397-402.

Cunha J, da Costa THM \& Ito MK (2005) Influences of maternal dietary intake and suckling on breast milk lipid and fatty acid composition in low-income women from Brasília, Brazil. Early Human Dev 81, 303-311.

Demmelmair H, Baumheuer M, Koletzko B, Dokoupil K \& Kratl G (1998) Metabolism of $\mathrm{U}^{13} \mathrm{C}$-labeled linoleic acid in lactating women. J Lipid Res 39, 1389-1396.

Hachey DL, Thomas MR, Emken EA, Garza C, Brown-Booth L, Adlof RO \& Klein PD (1987) Human lactation: maternal transfer of dietary triglycerides labeled with stable isotopes. J Lipid Res 28, 1185-1192.

Hellerstein MK, Christiansen M, Kaempfer S, Kletke C, Wu K \& Reid JS (1991) Measurement of de novo hepatic lipogenesis in humans using stable isotopes. J Clin Invest 87, 1841-1852.

Hunter D (1998) Biochemical indicators of dietary intake. In Nutritional Epidemiology, 2nd ed., pp. 174-243 [W Willett, editor]. New York: Oxford University Press.

Innis SM (1992) Plasma and red blood cell fatty acid values as indexes of essential fatty acids in the developing organs of infants fed with milk or formulas. $J$ Pediatr 120, 78S-86S. 
Jensen RG (1999) Lipids in human milk. Lipids 34, 1243-1271.

Jensen RG, Bitman J, Carlson SE, Couch SC, Hamosh M \& Newburg DS (1995) Milk lipids: A. Human milk lipids. In Handbook of Milk Composition, pp. 495-575 [RG Jensen, editor]. San Diego, CA: Academic Press.

Jensen RG, Lammi-Keefe C \& Koletzko B (1997) Representative sampling of human milk and the extraction of fat for analysis of environmental lipophilic contaminants. Toxicol Environ Chem 62, 229-247.

Jones PJH \& Kubow S (1999) Lipids, sterols, and their metabolites. In Modern Nutrition in Health and Disease, 9th ed., pp. 67-94 [ME Shils, JA Olson, M Shike and AC Ross, editors]. Pennsylvania: Williams \& Wilkins.

Katan MB, Deslypere JP, van Birgelen PJM, Penders M \& Zegwaard M (1997) Kinetics of the incorporation of dietary fatty acids into serum cholesteryl esters, erythrocyte membranes, and adipose tissue: an 18month controlled study. J Lipid Res 38, 2012-2022.

Koletzko B \& Rodriguez-Palmero M (1999) Polyunsaturated fatty acids in human milk and their role in early infant development. J Mammary Gland Biol Neoplasia 4, 269-284.

Kramer JKG, Fellner V, Dugan MER, Sauer FD, Mossoba MM \& Yurawecz MP (1997) Evaluating acid and base catalysts in the methylation of milk and rumen fatty acids with special emphasis on conjugated dienes and total trans fatty acids. Lipids 32, 1219-1228.

Lepage G \& Roy CC (1986) Direct transesterification of all classes of lipids in a one-step reaction. J Lipid Res 27, 114-120.

Lin H, Boylston TD, Chang MJ, Luedecke LO \& Shultz TD (1995) Survey of the conjugated linoleic acid content of dairy products. $J$ Dairy Sci 78, 2358-2365.

Lowry OH, Rosebrough NJ, Farr AL \& Randall RJ (1951) Protein measurement with the Folin phenol reagent. J Biol Chem 193, 265-275.

Macdiarmid J \& Blundell J (1998) Assessing dietary intake: who, what and why of under-reporting. Nutr Res Rev 11, 231-253.

Marangoni F, Agostoni C, Lammardo AM, Bonvissuto M, Giovannini M, Galli C \& Riva E (2002) Polyunsaturated fatty acids in maternal plasma and in breast milk. Prostaglandins Leukot Essent Fatty Acids 66, 535-540.

Martin J-C, Bougnoux P, Fignon A, Theret V, Antoine JM, Lamisse F \& Couet C (1993) Dependence of human milk essential fatty acids on adipose stores during lactation. Am J Clin Nutr 58, 653-659.

Monteiro CA, Mondini L \& Costa RBL (2000) Mudanças na composição e adequação da dieta familiar nas áreas metropolitanas do Brasil (1988-1996) [Changes in composition and appropriate nutrition of family diet in the metropolitan areas of Brazil (1988-1996)]. Rev Saúde Pública 34, 251-258.

Monteiro CA, Mondini L, de Souza AL \& Popkin BM (1995) The nutrition transition in Brazil. Eur J Clin Nutr 49, 105-113.

NEPA/UNICAMP (Núcleo de Estudos e Pesquisas em Alimentos/Universidade Estadual de Campinas) (2004) Tabela Brasileira de Composição de Alimentos - TACO [Brazilian Food Composition Table - TACO]. Campinas, Brazil: UNICAMP/ Ministério da Saúde.

Neville MC \& Picciano MF (1997) Regulation of milk lipid secretion and composition. Annu Rev Nutr 17, 159-184.

Ney JG, Torres AG \& Trugo NMF (2004) Análise de ácidos graxos nãoesterificados de plasma humano por cromatografia gasosa capilar com injeção sem divisão de fluxo [Analysis of nonesterified fatty acids in human plasma by capillary gas-chromatography with splitless injection]. Quím Nova 27, 561-566.
Pariza MW, Park Y \& Cook ME (2000) Mechanisms of action of conjugated linoleic acid: evidence and speculation. Proc Soc Exp Biol Med 223, 8-13.

Park Y, McGuire MK, Behr R, McGuire MA, Evans MA \& Shultz TD (1999) High-fat dairy product consumption increases $\Delta 9 c, 11 t-18: 2$ (rumenic acid) and total lipid concentrations of human milk. Lipids 34, 543-549.

Perry NA \& Doan FJA (1950) A picric acid method for the simultaneous determination of lactose and sucrose in dairy products. J Dairy Sci 33, $176-185$.

Polette A, Durand P, Floccard B \& Blache D (1992) A method for specific analysis of free fatty acids in biological samples by capillary gas chromatography. Anal Biochem 206, 241-245.

Precht D \& Molkentin J (1997) Effect of feeding on conjugated cis delta 9, trans delta 11-octadecadienoic acid and other isomers of linoleic acid in bovine milk fats. Nahrung 41, 330-335.

Rocquelin G, Tapsoba S, Dop MC, Mbemba F, Traissac P \& MartinPrével Y (1998) Lipid content and essential fatty acid (EFA) composition of mature congolese breast milk are influenced by mothers' nutritional status: impact on infants' EFA supply. Eur J Clin Nutr 52, $164-171$.

Silva MHL, Silva MTC, Brandão SCC, Gomes JC, Peternelli LA \& Franceschini SCC (2005) Fatty acid composition of mature breast milk in Brazilian women. Food Chem 93, 297-303.

Torres AG, Meneses F \& Trugo NMF (2000) Fatty acid content of erythrocyte membrane in Brazilian lactating women and its relation with dietary intake. FASEB $J$ 14, A209.

Torres AG, Meneses F \& Trugo NMF (2002a) Content of conjugated linoleic acids, cis-9,trans-11, 18:2 and trans-10,cis-12, 18:2 in breast milk from Brazilian women: association with milk composition and diet. Adv Exp Med Biol 503, 273-274.

Torres AG, Ney JG, Ribeiro M \& Trugo NMF (2004) Plasma nonesterified fatty acid composition is different in lactating and in non-pregnant non-lactating women. Adv Exp Med Biol 554, 511-514.

Torres AG, Trugo NMF \& Trugo LC (2002b) Mathematical method for the prediction of retention times of fatty acid methyl esters in temperature-programmed capillary gas-chromatography. J Agric Food Chem 50, 4156-4163.

Trugo NMF, Donangelo CM, Koury JC, Silva MI \& Freitas LA (1988) Concentration and distribution pattern of selected micronutrients in preterm and term milk from urban Brazilian mothers during early lactation. Eur J Clin Nutr 42, 497-507.

United States Department of Agriculture - Agricultural Research Service (2000). USDA Nutrient Database for Standard Reference, Release 13. http://www.nal.usda.gov/fnic/foodcomp (accessed March 2001).

Vlaadingerbroek H \& Hornstra G (2004) Essential fatty acids in erythrocyte phospholipids during pregnancy and at delivery in mothers and their neonates: comparison with plasma phospholipids. Prostaglandins Leukot Essent Fatty Acids 71, 363-374.

Wolff RL, Bayard CC \& Fabien RJ (1995) Evaluation of sequential methods for the determination of butterfat fatty acid composition with emphasis on trans-18:1 acids. Application to the study of seasonal variations in French butters. J Am Oil Chem Soc 72, $1471-1483$.

World Health Organization (1995) The Use and Interpretation of Anthropometry, Technical Report Series No. 854. Geneva: World Health Organization. 